\title{
O INTERNALISMO SEMÂNTICO DE CHOMSKY E SUAS CRÍTICAS À SEMÂNTICA EXTENSIONAL
}

\author{
[ CHOMSKY'S SEMANTIC INTERNALISM AND HIS CRITICS TO EXTENSIONAL SEMANTIC ]
}

\author{
Adriano Marques Silva* \\ Universidade Federal do Rio Grande do Norte, Brasil
}

\begin{abstract}
RESUMO: Neste artigo proponho uma discussão sobre as críticas de Noam Chomsky à semântica extensional e como o internalismo chomskiano está estreitamente relacionado ao programa de investigação gerativista. $\mathrm{O}$ argumento central aqui apresentado é que o que faz essa interpretação extremamente coerente é a distinção de Chomsky entre uma semântica internalista e pragmática.
\end{abstract}

Palavras-chaVe: Internalismo semântico; pragmática; Filosofia da Linguagem; Filosofia da Linguística
ABSTRACT: In this paper I propose a discussion of Noam Chomsky's critiques of extensional semantics and how Chomskian internalism is closely related to the generative research program. The central argument presented here is that what makes this interpretation extremely coherent is Chomsky's distinction between an internalist semantics and pragmatics.

KEYWORDS: Philosophy of Language; Philosophy of Linguistics; Pragmatics; Semantic Internalism

\section{INTRODUÇÃ̃o}

Weste artigo proponho uma discussão sobre as críticas de Noam Chomsky 1 à semântica extensional e como o internalismo chomskiano está estreitamente ancorado ao programa de investigação gerativista. Argumento que o que faz essa interpretação possível/ coerente é a distinção de Chomsky entre uma semântica internalista e pragmática. Inicialmente, apresento uma distinção conceitual muito importante ao programa gerativista e ao pensamento chomskiano, a saber, a distinção entre língua $-\mathrm{I}$ e língua-E. A seguir, caracterizo o internalismo chomskiano, sintetizando e articulando as várias passagens em que o autor caracteriza sua posição programática em relação à semântica. Finalmente, apresento as críticas de Chomsky à semântica extensional e como elas se articulam de maneira coerente graças as distinções apresentadas anteriormente, o que permite ao autor traçar uma linha divisória entre semântica internalista e pragmática.

* Doutor em Filosofia pelo Programa Interinstitucional de Doutorado em Filosofia: Universidade Federal da Paraiba-UFPB, Universidade Federal de Pernambuco-UFPE e Universidade Federal do Rio Grande do Norte-UFRN. Estágio de doutorado-sanduiche na University of Maryland (EUA), com bolsa CAPES, sob orientação de Paul M. Pietroski. m@ilto: adrymarques@gmail.com 


\section{LÍNGUA-I: INTERNA, INDIVIDUAL E INTENSIONAL}

Como bem define Taylor (1984), a abordagem behaviorista predominante no início do século XIX assumia que, ao curso da aquisição da linguagem, as crianças são capazes de associar estímulos a certos comportamentos verbais. Mediante o processo de reforço as crianças automatizam essa associação, passam a adotar o comportamento verbal adequado aos estímulos. Porém, se as crianças apenas 'reproduzem' o que ouvem, como são capazes de compreender e produzir frases novas, até então não pronunciadas? Como, em outras palavras, explicar competência linguística, a capacidade do falante de falar e compreender um número potencialmente infinito de frases? Chomsky argumenta que para explicar o mecanismo responsável pela competência linguística é necessário formular hipóteses que possuam certo grau de abstração em relação à multiplicidade de dados conjugados na performance efetiva, contextualmente situada, dos falantes. A performance, argumenta Chomsky, depende de um número de fatores heterogêneos como a atenção, a memória, o grau de interesse, a expressividade, emotividade etc. Uma teoria científica sobre a performance precisa coordenar teorias de natureza heterogênea como a fisiologia auditiva, conhecimentos sobre a memória, sobre a atenção, entre outros, além, é claro, do conhecimento sobre a competência linguística. Para entender a diferença entre competência e performance, vejamos os seguintes exemplos (RUWET, 2001, p. 23):

(1) Eu gosto de comer alface.

(2) João admira mais Pedro do que Márcio.

(3) O vertebral silêncio a vela ínclita indispõe.

(4) Ocê mim faiz ri, sô.

O conhecimento implícito do falante competente do português reconhece um conjunto de propriedades presentes nessas sentenças: a sentença (1) é uma frase bem formada; a frase (2) é ambígua ('João admira mais x do que y'; 'João admira mais y do que Márcio admira y'); (3) é uma sentença não usual, pouco frequente (compreensível em contexto poético, presumivelmente). A sentença (4) é compreensível, porem é característica de um dialeto específico. Não se nega com isso que o juízo do falante possa ser remodelado em contextos específicos: a sentença (3) será perfeitamente compreensível em um contexto poético; a sentença (2) não será ambígua quando empregada em uma asserção; a sentença (1) pode ser ininteligível, caso seja usada para codificar uma mensagem secreta, oculta. Se é verdade que os falantes podem asserir (1)-(4) em diferentes (potencialmente infinitas) situações conversacionais, não se segue que a ambiguidade em (2), por exemplo, não seja um traço estrutural e que dispense descrição. Existem, portanto, segundo a heurística empregada pelo programa gerativista, razões para separar o estudo gramatical das frases do estudo do contexto de asserções.

Entendida como uma língua-I, uma gramática é vista como um sistema de regras que une os sinais fonéticos às interpretações semânticas. A sintaxe se encarrega de realizar cômputos sobre representações linguísticas, é o mediador entre som e sentido, entre representação fonética e interpretação semântica. Uma sentença consiste em uma sequência de sons que no modelo é representado por PF (Phonological Form, a Forma Fonética da sentença). Além disso, uma sentença possui um significado estrutural que no modelo é representado por LF (Logical Form, a Forma Lógica da sentença). Daniela \& Reiss (2008) explicam que o processador fonológico precisa receber informações categoriais e cabe à gramática oferecer as informações categoriais gerando, assim, a PF 
Logo, se um falante reconhece que $\mathrm{S}$ é uma sentença da língua portuguesa, ele reconhecerá esse som como unidade linguística. A PF é 'som estruturado', é a forma sonora 'recortada' segundo uma descrição estrutural. A LF é o nível da gramática responsável pela determinação parcial do significado linguístico (ex: resolução de escopo, atribuição de papel temático etc.). Isso significa que a informação semântica é formalmente representada em LF.

No programa gerativista, todo indivíduo linguisticamente competente é capaz, em qualquer momento, de emitir e compreender, espontaneamente, um número indefinido de frases, frases que ele nunca antes tinha ouvido ou pronunciado. 'Competência', em sentido chomskiano, corresponde à noção de algoritmo, capacidade de gerar certa classe de funções que mapeiam o som ao significado, sequências de itens lexicais em descrições estruturais hierárquicas. A descoberta dos princípios computacionais dá pistas sobre como falantes "calibram" as sentenças estranhas, as estratégias que eles empregam, seja ao lidar com sequências ininteligíveis de itens lexicais (i.e., 'sopa de palavras'), seja ao computar sentenças estranhas, exóticas, mas inteligíveis. Não se almeja a explicação do comportamento criativo, mas sim a elucidação de certas propriedades mentais estáveis na mente do falante-ouvinte. A competência é uma condição necessária, mas não suficiente, para o comportamento criativo.

A contraparte técnica da noção de competência é a 'geratividade'. Esse é um conceito técnico entendido como um procedimento computacional que gera expressões discretas e estruturadas. Trata-se de uma idealização de operações combinatórias básicas, elementares, capazes de gerar expressões complexas a partir de expressões mais simples. Para Chomsky, uma ciência da linguagem humana deve caracterizar linguagens de modo intensional, como certos procedimentos capazes de associar descrições estruturais e significado. Por conseguinte, o cerne da investigação gerativista consiste em descobrir os princípios computacionais subjacentes à linguagem humana. Essa distinção é capturada nos conceitos de Língua -I e Língua -E, que podem ser condensados nas seguintes definições:

(i) Língua-E: Conjunto de pares sinal-interpretação;

(ii) Língua-I: Conjunto de procedimentos que geram esses pares.

Língua-E designa certa concepção sobre a linguagem natural, que concebe as línguas naturais como objetos externos (símbolos, sinais acústicos etc.). Nessa acepção, línguas são essencialmente entidades públicas, sociais; as línguas possuem uma existência independente e podem ser estudadas em abstração aos estados psicológicos dos falantes-ouvintes, de sua estrutura cognitiva. Línguas seriam artefatos, análogos ao jogo de xadrez: caso os seres humanos não existissem, o jogo de xadrez não existiria, mas não se segue que as regras de xadrez sejam um dos ramos da psicologia. Sendo extensional, a língua é concebida como um conjunto de símbolos: o inglês, por exemplo, seria equivalente a um conjunto de sentenças compreendidas por certa população. Como explica Collins (2011), essa analogia entre linguagem e artefatos envolve uma confusão entre dependência e constituição: a linguagem depende dos estados mentais, mas não se segue que a linguagem seja constituída por estados mentais. O que se afirma no gerativismo é que os estados mentais traduzem e manipulam os estímulos linguísticos de forma bastante complexa, idiossincrática e não trivial.

No programa gerativista, a extensão, isto é, as sentenças geradas pelo procedimento algoritmo, não são o objeto de investigação, mas sim as restrições 
computacionais responsáveis pela articulação entre som e significado. Ou melhor, o objeto de estudo não é um conjunto de símbolos, mas os procedimentos gerativos subjacentes ao conhecimento tácito do falante-ouvinte. Chomsky enfatiza que a mente humana é capaz de gerar um número infinito de sentenças. Sendo assim, a especificação das sentenças da linguagem deveria refletir a competência internalizada do falanteouvinte. Não se trata, pois, de especificar o conjunto gramatical de sentenças, mas sim de revelar o procedimento gerativo subjacente à competência linguística do falanteouvinte.

De acordo com essa perspectiva, durante o processo de aquisição, as crianças internalizam um procedimento gerativo que permite a geração e compreensão de um número infinito de sentenças. Dentro de uma perspectiva biolinguística, explica Boeckx (2006), o processo de aquisição equivale a um processo de maturação das operações biologicamente implementadas, que tornam possíveis a produção e compreensão de expressões linguísticas.

Chomsky traça a distinção entre Língua-I e Língua-E inspirado na distinção entre função em extensão e função em intensão. Uma função em intensão é um procedimento algorítmico, ao passo que função em extensão são os pares input-output gerados pelo procedimento algorítmico. Ou seja, dadas duas funções extensionalmente equivalentes, $\mathrm{f}(\mathrm{x})$ e $\mathrm{g}(\mathrm{x})$, não está excluída a possibilidade de que o padrão inputoutput exibido por ambas tenha sido formado a partir de algoritmos diferentes. Eis uma pequena amostra de funções extensionalmente equivalentes, mas intensionalmente distintas:

(1) $\mathrm{F}(\mathrm{x})=|\mathrm{x}-1|$

(2) $\mathrm{F}(\mathrm{x})=+\sqrt{ }(\mathrm{x} 2-2 \mathrm{x}+1)$

(3) $\{\ldots,<-2,3>,<-1,2>,<0,1>,<1,0>,<2,1>, \ldots\}$

(7) $\mathrm{G}(\mathrm{x})=\mathrm{x}+1$

(8) $\mathrm{G}(\mathrm{x})=3 \sqrt{ }(\mathrm{x} 3+3 \mathrm{x} 2+3 \mathrm{x}+1)$

(9) $\{\ldots,<-2,-1>,<-1,0>,<0,1>,<1,2>,<2,3>, \ldots\}$

Como podemos ver, do ponto de vista estritamente extensional, essas funções são equivalentes, indistinguíveis. Contudo, do ponto de vista intensional, (1) e (2) e (3) são funções distintas, uma vez que descrevem procedimentos diferentes. Dado o perfil de uma função (i.e., o padrão input-output exibido), '<-2, -1>', por exemplo, existem várias funções intesionalmente distintas capazes de computá-lo.

É um resultado bastante conhecido em psicolinguística, que um mesmo juízo de gramaticalidade pode ser compatível com diferentes estratégias de parsing (i.e., grosso modo o processo de análise, de decodificação do sinal linguístico). E que os juízos não necessariamente revelam a estratégia de parsing empregada pelo falante. Assim, dada uma sentença como:

(10) Maria costurou as meias caíram

Embora os falantes encontrem dificuldade em processar esse tipo de sentença (pois verbo 'costurar' exige um argumento interno do tipo NP que, no entanto, não se encontra realizado), esse fator não prediz o juízo que os falantes emitirão sobre ela. Os falantes interpretarão (10) como uma sentença coordenada ('Maria costurou e as meias caíram'), ou como duas sentenças não coordenadas (uma sentenças elíptica, 'Maria costurou x', e uma sentença completa, 'as meias caíram'). Ou seja, o juízo consciente emitido pelos falantes não revela o procedimento gerativo, psicolinguístico, empregado 
de maneira tácita, inconsciente. Conversamente, a estratégia de processamento não prediz o juízo que os falantes emitirão. Parte considerável da pesquisa psicolinguística consiste em divisar métodos empíricos capazes de trazer à luz a distinção entre os juízos de gramaticalidade conscientemente expressos pelos falantes e os mecanismos de processamento subjacentes.

A faculdade da linguagem é um sistema cognitivo que possibilita a aquisição e o uso de certa classe das línguas adquiríveis. No recorte metodológico traçado pelo programa gerativista, a faculdade da linguagem é constituída por dois componentes: o sistema cognitivo responsável pela computação da informação linguística, e os sistemas de performance (i.e., sistemas perceptuais) que utilizam o conhecimento linguístico alojado. Como a Língua-I é um procedimento algorítmico biologicamente instalado na mente humana, ela não pode ser identificada como um sistema estático instanciado na mente dos falantes-ouvintes. Como qualquer outro órgão, ela está sujeita ao desenvolvimento, maturação, etc. Sendo assim, quando nós dizemos que "o" português brasileiro possui tais e quais características significa, a rigor, que certo conjunto de indivíduos, a partir interações com o ambiente e outros falantes, tem instanciado em suas mentes certas propriedades da Língua-I, um sistema internalizado que os permite produzir e compreender um número potencialmente infinito de sentenças.

Vale salientar que Chomsky reconhece que o estado efetivo da faculdade da linguagem em um indivíduo é produto da interação entre inúmeros fatores de natureza contextual, cultural e idiomática. Porém, ele questiona se esse complexo conjunto de fatores pode ser abordado como uma unidade inteligível, explicável em um modelo científico, ou melhor, em um modelo científico que atenda aos requisitos e objetivos de uma investigação naturalística da língua.

Ludlow (2011) enfatiza que o modo de aquisição dos princípios linguísticos pela criança não coincide com o modo com que esses princípios são descobertos e explorados pelo linguista. Com efeito, o trabalho deste último consiste em descobrir generalizações não triviais e formular princípios que as expliquem. A criança, evidentemente, não aprende esses princípios reguladores de forma explícita, consciente. Esses princípios são implementados espontaneamente, pois eles regulam o espaço de línguas humanas possíveis, biologicamente adquiríveis. Tais princípios unificam uma grande variedade de dados linguísticos, não são ensinados e se aplicam a comunidades linguísticas bastante diversas. É importante esclarecer que o modo como o léxico é distribuído entre as comunidades linguísticas pode ser diferente. Contudo, as distinções estruturais serão respeitadas. O gerativismo afirma que são as limitações interpretativas internas que garantem que, em uma comunidade linguística heterogênea, a competência linguística das crianças convirja: elas atingem um estado cognitivo determinado, relativamente estável. As diferenças de inteligência possuem uma influência muito pequena sobre o estágio final, o conhecimento internalizado da língua, a competência linguística.

$\mathrm{Na}$ próxima sessão, veremos como as distinções fundamentais ao programa gerativista, apresentadas nessa sessão, se refletem no modo como Chomsky caracterizará o internalismo semântico.

\section{O InTERnALISMo SEMÂNTICo}

Em Chomsky (2000), o fundador do gerativismo apresenta várias considerações em relação à semântica contemporânea e conjectura qual seria o formato geral de uma semântica dentro do projeto gerativista. Essas considerações refletem o estágio de 
investigação mais recente do gerativismo, o Programa Minimalista (1995). Nesse modelo, a faculdade da linguagem (FL) é um sistema computacional (S-C) que atua sobre um léxico, gerando, para cada item lexical, uma PF (forma fonética) e uma LF (forma lógica ${ }^{1}$ ) as quais, por seu turno, estão na interface com outros sistemas cognitivos. Além disso, há uma operação Spell-Out que alimenta as interfaces. Esquematicamente, temos:

(i) O léxico (dicionário) contém os itens lexicais, compostos por traços fonológicos e semânticos, além de informações relativas sobre a estruturação sintática desses itens;

(ii) Um componente computacional que combina esses itens lexicais.

A faculdade da linguagem é responsável pela computação dos componentes internos, materiais, do léxico, a saber: os traços fonéticos e semânticos. Os itens lexicais são formados a partir da combinação desses componentes e as sentenças são formadas pela combinação de itens lexicais hierarquicamente concatenados. Do ponto de vista estrutural, os itens lexicais nada mais são do que conjuntos de traços fonéticos e semânticos; é sobre esses traços que o sistema computacional (S-C) se aplica, gerando expressões linguísticas. O sistema computacional seleciona itens do léxico e confere a esses itens uma forma fonética e uma forma lógica. Desse modo, cada expressão gerada corresponde a um par legível em PF e interpretável em LF. Assim, a sentença "João ama Maria", por exemplo, corresponde ao par PF, LF respectivamente: uma descrição fonética estrutural (i.e., uma sequência ordenada e estruturada de sons), sintática (i.e., uma estrutura hierárquica de constituintes, responsável pela concatenação das palavras) e semântica (ex: atribuição de papel temático, caso etc.).

Em suma, a teoria gramatical fornece a representação fonética, sintática e semântica do léxico.

No modelo computacional não entra em consideração a denotação de itens lexicais como "João" e "Maria". Eles não fazem parte do sistema computacional, pois a denotação não é determinada pelo processamento linguístico. São os falantes, em contextos particulares de uso, que empregam os itens lexicais para referir a entidades no mundo, de acordo com seus interesses, intenções etc. Nesse modelo, a referência e questões correlatas estão além do sistema linguístico, dizem respeito à pragmática. Contudo, para Chomsky, se uma teoria do contexto requer, em última instância, um conhecimento total da realidade (i.e., intersecção entre a realidade natural, social e cultural) ela não pode ser assumir a forma de um modelo.

$\mathrm{SEMs}^{2}$ é um conceito caro ao Programa Minimalista. Trata-se de um construto teórico que Chomsky utiliza em lugar de LF, para representar as perspectivas semânticas em potencial fornecidas pelos itens lexicais ao serem computados pela faculdade da linguagem. SEMs constituiriam os inputs para o módulo conceptualintencional, i.e., as perspectivas de categorização e referência disponíveis aos falantes e que possibilitam seu engajamento em atividades comunicativas, e para que eles possam lidar com o mundo ao seu redor. Elas não provem diretamente do mundo, são antes capacidades de conceitualização que possibilitam a interação dos falantes com o mundo. São, por hipótese, entidades mentais que traduzem os inputs linguísticos para o módulo concepto-intesional. Chomsky não se preocupa em definir 'significado'. Esse termo pré-teórico, intuitivo, corresponderá, afinal, a um conceito técnico assimilável na heurística da Gramática Gerativa. Dirá respeito à contribuição da Língua-I (procedimento algorítmico internalizado pelos falantes) na geração das capacidades humanas específicas. Nesse sentido, SEMs são entidades sintáticas. São descrições 
teóricas fornecidas pela GG a respeito do significado linguístico. Incluem traços semânticos e categoriais e não a relação linguagem-mundo como termo teórico, explicativo. A explicação da relação entre linguagem-mundo pode ser encarada como um objetivo último ('ousado') da teoria semântica. Um ponto de chegada ideal, mas não um ponto de partida da investigação. A ideia ainda é embrionária no Programa Minimalista, não é um construto bem articulado no formalismo sintático, mas uma entidade teórica postulada para lidar com a interface entre o sistema linguístico e os sistemas conceptuais. SEM seria a análogo a PHON. Ambos seria instruções: o segundo instruções enviadas para o sistema articulador. O primeiro, instruções para o sistema concepto-intesional. Assim, os itens lexicais consistiriam em pares de instruções. As instruções geram conceitos e sons de certo tipo.

Chomsky (2004) afirma que ainda é cedo para elegermos uma proposta teoricamente robusta e coerente sobre a psicologia de conceitos, assim como não ainda há, em geral, teorias satisfatórias acerca dos processos que estão além da faculdade da linguagem. Sendo assim, parece oportuno (e quiçá produtivo) investigar as condições estruturais que participam da computação linguística e são responsáveis pela interface sintaxe-semântica.

\section{As Críticas de Chomsky à Semântica Extensional}

Taylor (1985) explica que o sistema de Frege assumia a existência de um "conceito" (de cunho platônico) para cada fórmula aberta de sua linguagem, bem como uma "extensão " para cada conceito. Mais precisamente:

(i) Para todo predicado ' $\mathrm{P}$ ' existe um conceito $\mathrm{C}$ i.e., um função que leva entidades a valores de verdade. C mapeará as entidades em V sse elas caírem sob o conceito indicado por $\mathrm{P}$;

(ii) Todo conceito possui uma extensão i.e., um conjunto de entidades denotadas pelo conceito.

Como sabemos, Frege não estava preocupado em lançar hipóteses sobre a Faculdade da linguagem. Seu objetivo voltava-se para questões relativas à Filosofia da Matemática. Não obstante, na história da semântica formal, o significado de uma expressão linguística é identificado com objetos que ele denota, sejam objetos de senso comum, como particulares concretos (rochas, lagartos etc.) ou abstratos. O estudo da semântica revelaria o 'mobiliário do mundo', uma ontologia dos objetos que povoam a realidade. Tendo em mente a interface entre sintaxe-semântica, vejamos como essas assunções são traduzidas, os conceitos técnicos correspondentes (HEIM \& KRATZER, 1998).

No modelo de interpretação, uma função proposicional denota um conjunto de entidades, a saber, o conjunto de entidades que satisfazem a função. Funções proposicionais determinam o mapeamento de um conjunto de entidades no conjunto de valores de verdade. Como resultado desse mapeamento, temos o subconjunto das entidades que tornam a função verdadeira e o subconjunto das entidades que tornam a função falsa.

A notação padrão utilizada para escrever funções em linguística é a notação lambda, criada pelo matemático Alonzo Church ${ }^{3}$. Por exemplo, X.X ${ }^{2}$ é uma função que toma $\mathrm{x}$ como argumento e o mapeia em $\mathrm{x}^{2}$. A variável ' $\mathrm{x}$ ' pertence ao conjunto das entidades (tem o tipo lógico e) e as expressões complexas pertencem ao conjunto das 
sentenças (possuem o tipo t). Assim, uma expressão é uma função de entidades em valores de verdade, possui o tipo $<\mathrm{e}, \mathrm{t}>$. Assim, em (1):

$$
\text { (1) }<\text { Maria, nadar }>
$$

O significado de 'Maria' será a entidade denotada por esse item, a saber, Maria. O significado de 'nadar' será uma função que toma um indivíduo x e o mapeia em uma proposição que pareia $\mathrm{x}$ à propriedade de nadar: $\lambda \mathrm{x} .<\mathrm{x}$, nadar $>$. Essa função seleciona Maria como argumento. Obtemos, assim, o resultado desejado:

(2) $[\lambda x .<x$, nadar $>]($ Maria $)=<$ Maria, nadar $>$

Analogamente, na sentença 'Maria vê João' 'Maria' refere-se a um indivíduo, Maria, e 'João' refere-se a outro indivíduo, João. Essa sentença corresponde à seguinte proposição: <<Maria, João $>$, ver $>$. A proposição é um par ordenado cujos membros são < Maria, João >, de um lado, e a relação “ver". Essa proposição será verdadeira se e somente se a relação entre os indivíduos se der, isto é a proposição será verdadeira se, e somente se, Maria vê João.

A composição semântica corresponde à aplicação funcional, que toma como constituintes nódulos irmãos: um nódulo será o predicado, e o outro o argumento que satisfaz esse predicado. O significado de 'ver' é uma função que seleciona como argumento o significado de 'João' e tem como output o significado do VP:

(3) $\lambda x \lambda x .<<y, x>$, ver $>$

Essa função seleciona 'João' e 'Maria' como seus argumentos:

(4) $[\lambda x . \lambda y .<<y, x>$, ver $>]$ (João)

$={ }_{i}^{\lambda} \mathrm{y} \cdot<<\mathrm{y}, \mathrm{João}>$, ver $\left.>\right]$ (Maria)

(5) $\lambda \times . \lambda x .<<y, x>$, ver $>$

A função resultante, $\lambda$ y . $<<$ y,João $>$, ver $>$, corresponde ao significado do VP. O VP seleciona como argumento o significado de seus 'filhos' (ver as definições localizadas na seção 1.4 .2 , p. 52):

(6) $[\lambda$ y $\lambda<<$ y,João $>$, ver $>]$ (Maria)

$=<<$ Maria, João $>$, ver $>$

Essa última função computa o significado da sentença. Do ponto de vista denotacional, verbos são tomados como relações e propriedades ou ainda como funções, literalmente, e o significado das palavras como entidades matemáticas, objetos abstratos. A crítica de Chomsky segue-se diretamente do internalismo adotado pelo programa gerativista: parece estranho falar que o significado de um verbo é uma função, pois funções são objetos abstratos. Haveria um problema em aberto, o de explicar o que esse modelo está modelando, que tipo de fenômeno esta sendo explicado pelo modelo.

O propósito é claro, emular uma assimetria semântica análoga à assimetria sintática. Costuma-se assumir que "semântica" e "sintaxe" são áreas de investigação 
fundamentalmente distintas. Essa distinção parece razoavelmente clara em lógicamatemática, onde a "sintaxe" consiste apenas em regras de boa formação, definidas a partir de símbolos primitivos do sistema. Já a "semântica" fornece as condições de satisfabilidade, em um modelo, das sentenças bem formadas. Nessa acepção técnica, a sintaxe fornece o conjunto de estruturas passíveis de interpretação. Contudo, para que essa distinção funcione, é necessário admitir que existe uma função que relaciona os domínios da 'semântica' e da 'sintaxe', que existe uma relação biunívoca entre estrutura e significado. Dado um modelo, não é lícito correlacionar interpretações diferentes à mesma fórmula bem formada, nem atribuir a mesma interpretação à fórmulas distintas. Sistemas lógicos não toleram ambiguidade. Neles, sintaxe e semântica são distintas, ao contrário do que ocorre nas línguas naturais. As críticas de Chomsky dirigem-se ao modo como essa divisão técnica influencia as concepções usuais sobre linguagem natural e, sobretudo, sobre sua semântica.

É também ubiquamente aceito que a tarefa central de uma teoria semântica consiste em especificar as condições de verdade, satisfabilidade e referência das sentenças da linguagem natural, o conteúdo proposicional por elas expresso. Espera-se que a teoria semântica explique a relação entre linguagem e mundo, como o significado medeia a relação entre linguagem e mundo. Compreender uma expressão é estar em contato com o mundo, ainda que de forma indireta. Chomsky não se opõe à semântica formal, mas critica esse pressuposto.

Sua posição pode ser condensada nos seguintes tópicos (CHOMSKY, 2012):

(i) Rejeição da assunção de que existe uma relação transparente entre estrutura da linguagem e estrutura do mundo externo;

(ii) Separação entre termos coloquiais científicos: a ciência inventa novos conceitos, ela não descobre essências, seja da água, de montanhas, significado;

(iii) Rejeição de questões ontológicas fora do âmbito de um framework teórico delimitado;

(iv) Separação entre linguagem e uso da linguagem: para fins de investigação, são investigadas certas propriedades matemáticas, estruturais da linguagem humana (i.e., a Língua-I);

(v) Rejeição da autonomia do significado: sentenças e palavras não possuem significados plenos, dissociáveis de uma complexa inter-relação entre crenças, contexto, etc.

D’Agostino (1986) salienta que a posição de Chomsky em relação à interpretação denotacional da semântica é intimamente irmanada ao trabalho empírico e teórico desenvolvido por ele e outros colaboradores; são teses que surgem da reflexão da investigação empírica. De fato, como podemos ver, as proposições acima estão, em maior ou menor grau, associadas ao programa gerativista, às diretrizes metodológicas que servem de lastro à investigação empírica. As proposições (ii)-(iv) são o reflexo direto de uma escolha metodológica, o internalismo. As proposições (i) e (v), por seu turno, resumem a posição filosófica de Chomsky a respeito da natureza do significado. Veremos, no que se segue, uma exposição condensada das críticas de Chomsky. Os exemplos e os argumentos de Chomsky serão retomados e discutidos várias vezes ao longo da tese.

A posição de Chomsky a respeito da semântica incorpora as críticas deflagradas a partir da segunda metade do século XX com a virada pragmática (Taylor, 1985), segundo a qual muitos problemas semânticos acumulados pela filosofia analítica de tradição lógico formal, tradição predominante durante o início do século $\mathrm{XX}$, foram 
resolvidos ou mesmo dissolvidos pela análise do uso linguístico. Chomsky afirma que sua concepção de 'significado' está mais próxima daquela defendida por Austin e Wittgenstein. Em vários artigos e livros ele insiste que itens linguísticos (i.e., palavras e sentenças) são usados em uma miríade de funções: para referir, descrever, asserir, insistir, caçoar. O uso linguístico é uma forma de ação e ação é livre, não é passível de estudo, embora seja possível descrever certas correlações interessantes (como, por exemplo, a teoria dos atos de fala). Em certas circunstâncias itens linguísticos são usados para referir ou denotar aspectos e eventos do mundo. São usados para representar coisas, estados de coisas, circunstâncias etc. Não há dúvida quanto a esse ponto. Contudo, argumenta, não se segue que exista uma relação de referência entre os itens linguístico, em si mesmos, e seus referentes. Não são os itens mesmos que referem. São as pessoas, ao fazer uso desses itens, que referem. Não é necessário, muito menos incontroverso assumir, por exemplo, que um verbo como 'cantar' corresponde a um predicado unário, satisfeito por indivíduos que são cantores. Ademais, como não é possível determinar a extensão de predicados vagos (i.e., não é possível determinar os membros que 'caem' sob a extensão do predicado) parece duvidoso que a extensão de um predicado possa ser tomada como seu valor semântico. As fórmulas metalinguísticas empregadas em semântica formal estariam condenadas ao status de 'expressões híbridas', paráfrases semi-formais, que não caracterizam funções.

Vejamos alguns exemplos problemáticos para a semântica formal tal como tradicionalmente concebida (Chomsky 2000):

(1) A França é hexagonal e é uma república

(2) Este governo faz muito pouco pelo brasileiro médio, cujos filhos herdarão o déficit previdenciário

(3) Hamlet viveu com seus pais na Dinamarca

(4) Monociclos têm rodas.

Se existe uma teoria semântica extensional subjacente às línguas naturais, então o domínio de entidades denotadas pelos itens lexicais deveria ser especificável, ao menos em princípio. É necessário assumir que os valores sentenciais são composicionalmente determinados e mais que isso, que cada valor sentencial corresponde a um valor de verdade. O problema é a vagueza: como determinar uma função se a extensão do predicado é vaga, não pode ser determinada com precisão? Em (1) parece difícil discernir que tipo de entidade pode ser considerado o portado dos predicados 'ser hexagonal' e 'ser uma república'. É possível encontrar contextos em que a sentença (1) possua significado e seja verdadeira. Contudo, indaga Chomsky, isso implica que exista algo que seja hexagonal e uma república? Qual é, em outras palavras, o portador capaz de satisfazer propriedades tão distintas? Logo, embora (1) seja uma sentença inteligível, seu significado não pode, prima facie, ser composicionalmente definido. Em (2) o problema consiste em especificar a referência do sintagma nominal 'o brasileiro médio'. Qual a sua extensão? Como determiná-la? Como, por conseguinte, determinar a extensão do predicado 'ter filhos', presumivelmente atribuído a essa entidade? Em (3) temos um exemplo reconhecidamente complexo, envolvendo entidades ficcionais. É possível encontrar circunstâncias em que (3) tem significado e é verdadeira. Contudo, qual o portador de verdade dessa sentença?

Como determinar a extensão do predicado 'ter filhos', presumivelmente atribuído 'o brasileiro médio'? Em (3) temos um exemplo reconhecidamente complexo, envolvendo entidades 
ficcionais. É possível encontrar circunstâncias em que (3) tem significado e é verdadeira. Contudo, qual o portador de verdade dessa sentença?

A sentença (4) parece envolver consequências anti-intuitivas, pois (4) será verdadeira se cada monociclo tiver rodas (i.e., mais de uma roda). Ou seja, as condições de verdade expressas no esquema T para a sentença parecem autorizar instâncias como:

(5) João tem um monociclo

(6) Logo, o monociclo de João tem rodas.

Contudo, sabemos intuitivamente que a sentença (4) será verdadeira se cada monociclo tiver uma (e apenas uma) roda. É fácil perceber que a verdade da sentença (4) não garante a verdade da sentença (5). Já as sentenças (4) e (5), por contraste, a verdade da sentença (4) implica na verdade da sentença (6):

(7) Carros têm rodas

(8) João tem um carro

(9) Logo, o carro de João tem rodas

Considere ainda o seguinte par de sentenças:

(10) Castores são mamíferos

(11) Castores constroem represas

Em (10), o predicado "ser mamífero" aplica-se à espécie “castores”. Em (11), esse predicado aplica-se ao conjunto prototípico de castores (i.e., aqueles que vivem em floresta, não em laboratório etc.). Essa pequena amostra aponta as dificuldades de assinalar condições de verdade às sentenças da linguagem natural. Esses exemplos são um indício de características substanciais, robustas, presentes na linguagem natural: itens lexicais possuem uma textura flexível, introduzem vagueza e flexibilidade características das línguas naturais. Em todos os exemplos, a determinação das condições de verdade parece depender de um conjunto heterogêneo de fatores, o que garante sutis diferenças na atribuição de condições de verdade de cada sentença.

O problema em adotar uma teoria da verdade como base para uma teoria semântica das línguas naturais consiste no fato dela ter de lidar com um número incrivelmente diversificado de entidades. Creio que um semanticista laborioso (e persistente) poderia, a princípio, contornar os problemas trazidos pela natureza aberta, flexível, das línguas naturais (ex: fazendo paráfrases 'ontologicamente bem comportadas' das sentenças problemáticas). Contudo, mesmo que esse semanticista fosse bem sucedido, não significa que ele assentaria os pressupostos fulcrais assumidos pela semântica extensional. Pelo contrário, creio que as manobras deporiam contra a exequibilidade desse tipo de empreendimento: existem motivações independentes para adotar as manobras formais? Quais as virtudes explanatórias oferecidas pela teoria? O problema, em suma, é saber se existem motivações independentes para aceitar esses ajustes, ou se são apenas mudanças $a d$ hoc. As teorias da verdade acabam, por fim, fornecendo semânticas para versões arregimentadas das línguas naturais. Versões com ricas ontologias e paráfrases respeitosas, bem comportadas.

Com esses exemplos, Chomsky mostra que falantes podem usar um nome para denotar, simultaneamente, várias coisas. "Denotar" é tomado como uma relação entre palavra e mundo. Porém, critica Chomsky, esse tipo de estipulação não nos oferece uma teoria sobre a relação linguagem e mundo. Ele procura mostrar que o 
parco poder explanatório da semântica formal em explicar a relação entre linguagemmundo depõe contra esse tipo de empreendimento, desde suas bases. Logo, parece lícito questionar a pertinência desse tipo de abordagem ao estudo das línguas naturais, por oposição ao estudo de sistemas formais.

A desconfiança de Chomsky dirige-se à interpretação denotacional da metalinguagem, mas não ao aparato formal em si. Para o autor é um problema em aberto determinar o que as metalinguagem lógico-semântica explica, que tipo de explicações ela oferece se subtrairmos a crença injustificada de que teorias semânticas são teorias sobre condições de verdade. Para o autor, a própria noção intuitiva de 'significado' precisa ser esclarecida, não pode ser tomada como simples explanandum.

De forma simplificada, podemos dizer que de um lado a interpretação denotacional da semântica lógico-formal parte do pressuposto empírico de que as línguas naturais variam de forma indefinida, em todas as dimensões, são cronicamente arbitrárias, irregulares, não possuiriam nenhuma sistematicidade. Do outro lado, a abordagem pragmática constata que a complexidade dos fenômenos relativos à comunicação, verdade e referência seriam inabarcáveis pelas linguagens formais. Em ambos os polos, vale lembrar, não havia nenhum interesse no estudo da língua por si mesma: essas abordagens, por distantes que possam parecer, comungavam a ambição de solucionar (ou dissolver) problemas filosóficos tradicionais relativos à verdade, ao juízo etc. Chomsky oferece uma posição intermediária entre esses dois extremos: por um lado, ele emprega linguagens formais, mas sem a motivação (quixotesca, dirá Chomsky) de descrever os mecanismos que regem o uso linguístico. O formalismo está a serviço da investigação das propriedades matemáticas, estruturais da linguagem natural, ele não foi concebido para solucionar problemas complexos concernente à triangulação entre linguagem, contexto e mundo.

\section{ConCluSÃo}

Nesse artigo foi apresentada uma discussão sobre as críticas de Noam Chomsky à semântica extensional e como o autor caracteriza o internalismo semântico. Mostramos como o internalismo chomskiano está relacionado ao programa de investigação gerativista. Como vimos, o que faz essa interpretação coerente é a distinção de Chomsky entre uma semântica internalista e pragmática. Na sessão 1, foi apresentada uma distinção conceitual muito importante ao programa gerativista e ao pensamento chomskiano, a saber, a distinção entre língua -I e língua-E. it was presented the (...). Em 2, o internalismo chomskiano foi sintetizado e sua posição programática em relação à semântica. Finalmente, apresentei as críticas de Chomsky à semântica extensional e como elas se articulam de maneira coerente graças as distinções apresentadas anteriormente, o que permite ao autor traçar uma linha divisória entre semântica internalista e pragmática.

\section{REFERÊNCIAS}

BORG, E., Minimal Semantics. Oxford: Oxford UP, 2004.

BOECKX, C., Linguistic Minimalism. Oxford: Oxford UP, 2006.

CHOMSKY, N., Aspects of the Theory of Syntax. Cambridge: M.I.T, 1965. . Essays on Form and Interpretation. New York: North Holland, 1977.

Lectures on Government and Binding. Dordrecht, Holland: Foris Publications, 1981. 
. Knowledge of Language. New York: Praege, 1986.

O Conhecimento da Lingua: Sua Natureza, Origem e Uso. Lisboa, Editora Caminho, 1994. . Language and Nature. Mind 104:1-61, 1995.

. New Horizons in the Study of Language and Mind. Cambridge: Cambridge University Press, 2000.

. Three Factors in Language Design. In: Linguistic Inquiry. Volume 36, Issue:

1, 1-22, 2005.

. The Science of Language: Interviews with James McGilvray. Cambridge: Cambridge UP, 2012.

COOK, V., Chomsky's Universal Grammar. An Introduction. Malden, MA: Blackwell Publishers, 2007.

COLLINS, John. The Unity of Linguistic Meaning. Oxford: Oxford UP, 2011.

D'AGOSTINO, F., Chomsky's system of ideas. Oxford: Clarendon Press, 1986.

HEIM, I. \& KRATZER, A., Semantics in Generative Grammar. Cambridge: Blackwell Publishers, 1998.

LAKATOS, I., The Methodology of Scientific Reseach Programmes Cambridge: Cambridge UP, 1978.

LARSON, R. Semantics, in: L. Gleitman, (ed.), Invitation to Cognitive Science, Vol. 1. Language. Cambridge: MIT Press, 361-380, 1995.

LARSON, R. \& SEGAL, G., Knowledge of Meaning: an Introduction to Semantic Theory. Cambridge: MIT Press, 1995.

LEWIS, D., General Semantics, In: Semantics of Natural Language. D. Davidson \& G. Harman (eds.), D. Reidel, .169-218., 1972.

LUDLOW, P., Referential Semantics for I-languages?, In: L. Antony, \& N. Hornstein (eds.), Chomsky and his Critics. Malden, MA: Blackwell Pub., 140-161, 2003. . The Philosophy of Generative Linguistics. Oxford: Oxford UP.

OTT, D. (2017), Strong Generative Capacity and the Empirical Base of Linguistic Theory. In: Frontiers of Psychology, 8: 1617, 2011.

PIETROSKI, P. M., Function and Concatenation, In: G. PREYER, \& G. PETER (eds.), Logical Form and Language. Oxford: Clarendon Press, 91-131, 2002.

- Semantics and Metaphysics of Events, In: K. LUDWIG. (ed.). Contemporary Philosophy in Focus: on Davidson. Cambridge University Press, 137-162, 2003a.

The Character of Natural Language Semantics. in: A. BARBER (ed.), Epistemology of Language. Oxford: O.U. P., 217-256, 2003b.

. Events and Semantic Architecture. Oxford: O.U. P., 2005 a.

Meaning Before Truth, In: G. PREYER \& G. PETERS (eds.), Contextualism in Philosophy. Oxford: O.U. P, 253-300, 2005 b.

Meaning Before Truth Conditions (Handout) Avaliable in: http://www.terpconnect.umd.edu/ pietro/research/papers/Arizona1.pdf, 2005c.

. Character Before Content. In: J. THOMSON \& A. BYRNE. (eds.), Content and Modality: Themes from the Philosophy of Robert Stalnaker. Oxford: O.U.P., 34-60, 2006a.

. Interpreting Concatenation and Concatenates. In: Philosophical Issues, v. $16,221-45,2006 b$.

Systematicity via Monadicity. In: Croatian Journal of Philosophy, v. 7, 343-374, 2007.

Minimalist Meaning, Internalist Interpretation. In: Biolinguistics, v. 4, 317-341, 2008.

Concepts, Meanings, and Truth: First Nature, Second Nature and Hard Work . In: Mind and Language, v. 25, 247-78, 2010a.

Describing I-junctions (Not published) Avaliable at: http://terpconnect.umd.edu/ pietro/research/papers/ijunctions.pdf. 2010b. Minimal Semantic Instructions, In: C. BOECKX (ed.). The Oxford 
Handbook on Linguistic Minimalism. Oxford: O.U.P., 472-498, 2011.

Semantic Monadicity with Conceptual Polyadicity. In: The Oxford Handbook of Compositionality (M. Werning, W. Hinzen, and E. Machery, eds.), p. 129-48, Oxford University Press, 2012. . Framing Event Variables. In: Erkenntnis 80:31-60, 2015.

68 "Semantic Internalism". In: The Cambridge Companion to Chomsky (J. McGilvray, ed.), 196-216, Cambridge University Press, 2017.

PIETROSKI, P. M. \& HORNSTEIN, N. Does every Sentence like this Contain a Scope Ambiguity?, In: W. HINZEN, \& H. ROTT. (eds.), Belief in Meaning: Essays at the Interface, Hansel-Hohenhausen, 43-72.

. Basic Operations: Minimal Syntax-Semantics. In: Catalan Journal of Linguistics n. 8, 113-139, 2009.

PUTNAM, H. (1973), Meaning and Reference. In: Journal of Philosophy 70, 699-711, 1973.

RUWET, Nicolas. Introdução à Gramática Gerativa. São Paulo: Editora Perspectiva, 2001 .

STAINTON, R. J., Meaning and Reference: Some Chomskian Themes, In: E.LEPORE \& B.C.

SMITH (eds.), The Oxford Handbook of Philosophy of Language. Oxford: OUP., 913940, 2006.

TAYLOR, C., Philosophical Papers. Human Agency and Language. Cambridge University Press, 1985.

\section{Notas}

1 Forma lógica, em sintaxe gerativa, não significa sentença formal em lógica de predicados de primeira ordem, mas sim a conversão dos itens lexicais em descrições estruturais que explicitam exigências categoriais e semânticas de cada item.

2 Ver LUDLOW, Peter. Referential semantics for I-languages? In: ANTONY, L. \& HORNSTEIN, N. (eds.) Chomsky and his critics. Cambridge: Blackwell, 2003, p.140-161.

3 Chomsky tirou a inspiração do conceito de 'Língua-I' da ideia de função-comoprocedimento (i.e., função em intensão) defendida pro Church. Embora o cálculo lambda seja abundantemente utilizado em semântica formal a distinção entre função em extensão e função em intensão (que motivou a criação do cálculo lambda) é hoje ignorada, foi historicamente substituída pela interpretação denotacional da metalinguagem lógico-semântica. 